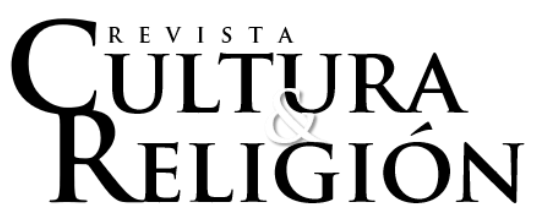

Vol. XIII, N 1 (2019) pp. 4-23

Recibido: 8 de diciembre, 2018

Aceptado: 20 de mayo, 2019

\title{
LA IGLESIA CATÓLICA CUBANA: ENTRE EL VATICANO II Y LA REVOLUCIÓN MARXISTA (1959 - 1966) ${ }^{1}$
}

\author{
Cuban Catholic Church: between the Second Vatican Council and the Marxist \\ revolution (1959 - 1966) \\ por \\ Felipe P. Valencia* \\ Universidad Laval, Quebec \\ felipe.perez-valencia.1@ulaval.ca
}

\begin{abstract}
Resumen
El presente trabajo analiza cómo la Iglesia católica cubana vivió la convocatoria, la preparación y la celebración del concilio Vaticano II. En Cuba, estas primeras fases del Vaticano II serán vividas en paralelo con la instauración del sistema socialista, como etapa previa a la construcción de la sociedad comunista. La construcción del socialismo, que asume el marxismo como ideología y metodología para la transformación social, supone la destrucción del sistema capitalista y de todas las instituciones que lo sustentan. Dado que para el marxismo la religión, como cosmovisión, y la Iglesia, como institución, han sido instrumentos de la clase dominante para ejercer su control sobre las clases explotadas, el aniquilamiento del capitalismo debe pasar inexorablemente por la desarticulación de la religión. Este principio, axial para la construcción del comunismo, creó una situación de enfrentamiento Estado-Iglesia Católica en Cuba. Así, mientras la Iglesia Católica Latinoamericana, bajo la influencia del Vaticano II, vivió la expansión más importante de su historia, el catolicismo cubano, bajo el sistema marxista, hubo de experimentar la peor retracción de su historia.
\end{abstract}

Palabras Claves: Concilio Vaticano II, Revolución Cubana, Catolicismo Cubano, Marxismo.

\footnotetext{
${ }^{1}$ Este artículo se enmarca en el proyecto "Vatican II et le Québec des années 60" (https://www.vaticanii.ulaval.ca/), proyecto internacional e interdisciplinar dirigido por el profesor G. Routhier

* Licenciado y master en Historia por la Universidad Central "Marta Abreu" de Las Villas. Becario doctoral (PhD en Sciences des religions) de la Universidad Laval.
}

Revista Cultura \& Religión Vol. XIII, 2019 № 1 (enero-junio)

Cómo citar este artículo: Valencia, F. (2019). "La iglesia católica cubana: entre el vaticano II y la revolución marxista (1959 - 1966)”. Revista Cultura \& Religión. Vol. 13(1). pp. 4-23. 


\begin{abstract}
This paper analyzes how the Cuban Catholic Church experienced the convocation, preparation and celebration of the Second Vatican Council. In Cuba, these first phases of Vatican II will be lived in parallel with the establishment of the socialist system, as a previous stage to the construction of the communist society. The construction of socialism, which assumes Marxism as the ideology and methodology for social transformation, presupposes the destruction of the capitalist system and all the institutions that sustain it. Since for Marxism religion, as a worldview, and the Church, as an institution, have been instruments of the ruling class to exercise its control over the exploited classes, the annihilation of capitalism must inexorably pass through the dismantling of religion. This principle, axial for the construction of communism, created a situation of State-Catholic Church confrontation in Cuba. Thus, while the Latin American Catholic Church, under the influence of Vatican II, experienced the most important expansion in its history, Cuban Catholicism, under the Marxist system, had to experience the worst retraction in its history.
\end{abstract}

Key words: Second Vatican Council, Cuban revolution, Cuban Catholicism, Marxism.

\title{
Planteamiento del problema
}

El concilio Vaticano II es el acontecimiento eclesial más trascendental del ya pasado siglo XX (Routhier, 2011). Su importancia superó los límites de lo eclesiástico para también incidir en la vida social y política de ciertas regiones y naciones (Guldberg \& González, 2006). Este es el caso de América Latina (Palacios \& Weinberg, 2008), donde las enseñanzas conciliares dieron una nueva dimensión a la visión y al lugar de la Iglesia en la sociedad.

Uno de los más importantes frutos del Vaticano II en Latinoamérica fue la deseuropeización de la Iglesia y de la teología católicas. Si bien la participación de los obispos latinoamericanos en las sesiones conciliares no puede ser juzgada de muy activa, al menos en comparación con la de los obispos europeos (Antoine, 1991), el regreso de los padres conciliares a sus conferencias nacionales fue el inicio de un dinamismo eclesiástico raramente experimentado en otras épocas y regiones (Morello, 2007). La interpretación del concilio a través de la lectura de los signos de los tiempos dio como resultado fundamental la implicación práctica de la Iglesia en las soluciones de los problemas más urgentes de las sociedades latinoamericanas (Antoine, 1999). Expresión de ello son: el surgimiento de las teologías de la liberación (Nieuwenbove, 1985) y de otros movimientos teológicos donde la problemática del hombre latinoamericano es abordada desde la superación de la visión caritativa hacia el pobre para asumir posiciones fácticas y proponer soluciones estructurales duraderas (Ivereigh, 2014); el surgimiento de las comunidades eclesiales de base (Marins, Trevisan \& Chanona, 1977); la radicalización hacia la izquierda política de una parte del clero y de la feligresía católica (Floristán \& Tamayo, 1985), la polémica entre el conservadurismo y el liberalismo teológico (Neves \& Bidegain, 1992), entre otras manifestaciones.

Revista Cultura \& Religión Vol. XIII, 2019 Nº 1 (enero-junio)

Cómo citar este artículo: Valencia, F. (2019). "La iglesia católica cubana: entre el vaticano II y la revolución marxista (1959 - 1966)”. Revista Cultura \& Religión. Vol. 13(1). pp. 4-23. 
Ahora bien, el sismo teológico-eclesiástico provocado por el concilio Vaticano II en Latinoamérica no se sintió con igual fuerza en Cuba. En la Isla caribeña, el llamado a la renovación del catolicismo fue vivido en paralelo con la denominada "Revolución Cubana", proceso político cuyo fin fue la renovación de todas las estructuras de la sociedad (Silva, Civeira \& Loyola, 2004). Una mirada, grosso modo, a la evolución del catolicismo cubano durante los años conciliares (1965 - 1965) nos muestra una iglesia ajena al gran pentecostés del catolicismo moderno. Para Raúl Gómez Treto, "este trascendental acontecimiento (el concilio Vaticano II) pasó casi inadvertido para la Iglesia Cubana, inmersa en tensiones y preocupaciones muy específicas” (Treto, 1987, p. 57). La pregunta es; ¿por qué en Cuba, país católico, el concilio Vaticano II no es vivido con la misma intensidad que en el resto de América Latina? ¿Cómo vivió el catolicismo cubano el primer Concilio celebrado en un mundo globalizado?

El artículo que a continuación proponemos tiene por objetivo identificar los factores que determinan que el concilio Vaticano II haya sido un hecho casi imperceptible para la Iglesia Católica Cubana. Asimismo, en el artículo se explicará cómo ocurre el proceso de repliegue y marginación del catolicismo cubano entre los años 1959 y 1966, etapa que coincide con un importante período de expansión de la Iglesia católica latinoamericana ${ }^{2}$.

\section{Vaticano II y Revolución cubana. Fronteras entre dos épocas.}

El Concilio Vaticano II y la Revolución Cubana son procesos que evolucionan en paralelismo cronológico. En enero de 1959, la dictadura de Batista es derrocada por la güerilla comandada por el joven abogado Fidel Castro y remplazada por un gobierno inicialmente democrático que posteriormente se orientará haca el marxismo (Cantón \& Silva, 2009). Durante el mismo mes, del otro lado del Atlántico, en Roma, Juan XXIII anunciaba a un reducido grupo de cardinales su intención de celebrar un sínodo en la diócesis de Roma, de convocar a un nuevo concilio ecuménico y de reformar el código canónico de 1917 (Theobald, 2009). En Cuba, entre 1959 y 1965, el nuevo gobierno desarticula la estructura capitalista para erigir las bases del sistema socialista, como etapa previa de la construcción de la sociedad comunista (Partido Comunista de Cuba, 1976). En 1965, como corolario de las profundas mutaciones estructurales sistémicas, surge el Partido Comunista de Cuba (PCC), único partido legalmente reconocido por el nuevo sistema sociopolítico (Cantón \& Silva, 2009). El monopolio de la ideología marxista anuló la participación en el proyecto político que se construía de aquellos -individuos o instituciones- cuya ideología o comportamiento social antagonizaba con los principios del marxismo.

\footnotetext{
${ }^{2}$ En los años posteriores a 1966, en la medida en que el proceso de recepción de las enseñanzas conciliares se consolida, el conflicto Estado-Iglesia católica se profundiza. Dicho conflicto, consecuencia directa de la recepción conciliar en un país comunista, involucrará a diversos elementos: agentes pastorales nacionales, órdenes religiosas llegadas a Cuba en épocas posteriores (como los Oblatos, llegados en 1997), instituciones surgidas en oposición al pensamiento católico tradicional cubano y que participan en el conflicto creando división en el catolicismo cubano (como el Centro Oscar A. Romera, fundado en 1984), entre otros.
}

Revista Cultura \& Religión Vol. XIII, 2019 Nº 1 (enero-junio)

Cómo citar este artículo: Valencia, F. (2019). "La iglesia católica cubana: entre el vaticano II y la revolución marxista (1959 - 1966)”. Revista Cultura \& Religión. Vol. 13(1). pp. 4-23. 
También en 1965 las cortinas de las sesiones conciliares caen. La Iglesia católica ha aprobado los documentos que la harán salir de su ghetto (Paraíso, 2013), conduciéndola por el camino de la reconciliación con la sociedad (Paraíso, 2013). El corto período 1959 - 1965, marca una frontera epocal tanto para la Historia cubana como para la Historia de la Iglesia Católica.

\section{Antecedentes del problema. Catolicismo y sociedad durante el siglo XX cubano.}

Cuando en 1959 los rebeldes toman el poder político en Cuba, la revolución social, así como la reestructuración política y económica de la nación, son necesidades urgentes. La república instaurada desde 1902 no ha funcionado del todo bien (Zanetti, 2006), a los problemas heredados de más de cuatro siglos de colonialismo se le han agregado los generados por un capitalismo liberal que ha debilitado la soberanía nacional (Yglesias, 1976). La Iglesia Católica nunca estuvo ajena a las dificultades de esta sociedad. Durante la primera mitad del siglo XX, el catolicismo cubano reconquista la fuerza social perdida desde los años '30 del siglo anterior (Létrilliart, 2013) a consecuencia de la supeditación de la Iglesia a la corona española (Maza, 1997). En el siglo XX, hasta la llegada de la izquierda marxista al poder, el catolicismo cubano se regenera y recupera la presencia social (Estiú, 1998). La influencia de la Iglesia católica en esta sociedad responde a que, a medida que los gobiernos se descargan de funciones que les son inherentes como rectores de la sociedad, la iglesia, con su organización, sus recursos humanos y sus limitados recursos materiales, los asume (Valencia, 2018). La creación de la Academia Católica de Ciencias Sociales en 1919, institución surgida para atender los problemas que enfrentaban a los sectores trabajadores cubanos con el capital extranjero (García, 2000), las numerosas obras sociales mantenidas por la iglesia católica para atenuar la crisis social (Junta Nacional de Acción Católica Cubana, 1953), los documentos producidos durante la guerra civil por importantes personalidades católicas, sobre todo por Monseñor Enrique Pérez Serantes (Conferencia de Obispos Católicos de Cuba [COCC], 1995), la incorporación de jóvenes católicos a las filas de la revolución (Conferencia Episcopal Cubana [CEC], 1987), son ejemplos que demuestran la implicación de la Iglesia en los problemas sociales de la república. El apoyo del catolicismo cubano a la revolución fue tan evidente que el 7 de enero de 1959, Fidel Castro lo juzgaba de extraordinario (Diario de la Marina, 1959a).

Cuando la Revolución Cubana triunfa, la reconstrucción de la nación forma parte de los intereses de casi todos los sectores sociales, incluida la Iglesia (Serantes, 1959a). Si bien especular sobre hechos que nunca sucedieron carece de todo rigor científico, creemos que la necesidad de renovación social, unido a la armonía que para ese entonces matizaba las relaciones entre el nuevo gobierno y la Iglesia Católica, crean condiciones favorables para la participación del catolicismo cubano en la reconstrucción de la sociedad cubana. Sin embargo, durante los años de preparación y celebración del concilio (1959 - 1965) la revolución humanista da un giro inesperado y adopta el marxismo como instrumental teórico para explicar la evolución de la sociedad cubana y como metodología política para reconstruir la

Revista Cultura \& Religión Vol. XIII, 2019 Nº 1 (enero-junio)

Cómo citar este artículo: Valencia, F. (2019). "La iglesia católica cubana: entre el vaticano II y la revolución marxista (1959 - 1966)”. Revista Cultura \& Religión. Vol. 13(1). pp. 4-23. 
nación. ¿Cómo afecta la adopción del marxismo la implicación de la Iglesia católica cubana en el concilio Vaticano II?

\section{El marxismo en Cuba, la nueva sociedad y los nuevos conflictos.}

La presencia del marxismo en el escenario político cubano se remonta a fines del siglo XIX (Massón, 2008) y coincide con el crecimiento -numérico- de la clase obrera cubana potenciado por la abolición de la esclavitud (Torres-Cuevas \& Loyola, 2001) y por el arribo de inmigrantes españoles en calidad de obreros (Rama, 1990). Durante el siglo XX, pese a su endeble influencia política, el marxismo sobrevive bajo diferentes organizaciones y partidos (Miranda, 1995). En los críticos años '50, cuando estalla la guerra civil en respuesta al mencionado golpe de Estado, los marxistas, reunidos bajo la denominación de Partido Socialista Popular (PSP) juzgan de erradas las acciones armadas dirigidas por Fidel Castro, “[...] el camino escogido por Fidel Castro y sus compañeros es falso [...], la acción armada desesperada y con categoría de aventura, no conducen a otra cosa que al fracaso, al desperdicio de fuerzas" (Carta Semanal, 1953). El triunfo de la revolución es el hecho que convierte al marxismo en ideología dominante de la vida política de la nación. La adopción del marxismo, ideología surgida en un contexto tan lejano en lo geográfico como en lo sociohistórico, por la clase política cubana que guiaba el proceso de reconstrucción de la nación, significó una violenta ruptura con la cultura, con la tradición, con las estructuras democráticas de la nación y con la relación Iglesia-Estado e Iglesia-Sociedad, especialmente con el catolicismo (CEC, 1987).

Una vez concretado el giro hacia el marxismo, el sistema comunista cubano se consolida. Entre 1961 y 1965, años conciliares, el Estado procede a reconfigurar la sociedad bajo el supuesto de organizarla a fin de repeler cualquier intento conservador, interno o externo, de frustrar la construcción de la sociedad socialista (Navarro \& León, 2009). Dicha reconfiguración tuvo tres escenarios fundamentales, la estructura política de la nación, la sociedad civil y la economía. Primeramente, la vida política de la nación se reduce a una estructura de partido único, donde el Estado queda supeditado al partido quien detenta todo el poder, dando lugar al sistema de "Partido-Estado" (Shivley, 2012, p. 107). En segundo lugar, la sociedad civil desaparece, siendo reemplazada por un conjunto de instituciones, penetradas y dirigidas por el partido-Estado. Finalmente, en el caso de la economía, la empresa privada desaparece, la base productiva de la sociedad pasa a manos del estado quien representa, en teoría, a la sociedad (Cantón \& Silva, 2009).

Pero la adopción del marxismo, asumido de manera acrítica en su versión soviética, significó, además, la introducción de una nueva concepción ideológica con fuerte influencia en la cultura, en la política y en la interpretación de la historia nacional, y cuyo eje es la lucha de clases (Marx \& Engels, 1948). En este contexto, la historia de la iglesia católica cubana fue reinterpretada, simplificada y embutida a la fuerza en el molde marxista. De golpe, el catolicismo cubano fue colocado del lado de los explotadores históricos de la sociedad cubana, culpándosele de haber servido de sustento ideológico a la explotación sufrida por los

Revista Cultura \& Religión Vol. XIII, 2019 № 1 (enero-junio)

Cómo citar este artículo: Valencia, F. (2019). "La iglesia católica cubana: entre el vaticano II y la revolución marxista (1959 - 1966)”. Revista Cultura \& Religión. Vol. 13(1). pp. 4-23. 
cubanos desde la génesis misma de la nacionalidad y de la nación (Acerca de la Religión, la Iglesia y los Creyentes, 1982). En consecuencia, la construcción de la sociedad comunista, sociedad donde las clases sociales desaparecen y con ello la dominación de una clase social sobre otra, debería pasar inexorablemente por la desconfesionalización -permítaseme el neologismo, ateización - de la sociedad. Sustraer la sociedad de toda influencia y de toda práctica religiosa, reduciendo la religión a una cuestión personal, estaría entre las prioridades del nuevo estado.

\section{La marginalización del catolicismo cubano en tiempo de concilio}

Aunque el período crítico en las relaciones Iglesia-Estado se inicia a partir de 1961, ya desde el año '59 ocurren hechos que conspiran contra la armonía Iglesia-Sociedad e Iglesia-Estado, alcanzada durante la primera mitad del siglo XX. Durante los dos primeros años de revolución hay tres momentos en que las acciones de la Iglesia y del Estado son contestadas recíprocamente, creando tensión en las relaciones Iglesia-Sociedad e IglesiaEstado, ellos son: (1) la aprobación de la Ley 11 de educación; (2) la posición adoptada por la Iglesia frente a los fusilamientos de los opositores a la revolución, y (3) la celebración del primer Congreso Nacional Católico como reacción de la Iglesia a la penetración comunista en el gobierno del país.

El primer evento que menciono tendría lugar en fecha tan temprana como el 13 de enero del '59 cuando el ministro de educación hizo aprobar la ley 11 (Cordoví \& Murgia, 2017). Dicha ley invalidaba los diplomas otorgados por las universidades privadas que habían continuado en servicio durante la guerra civil (Uría, 2011). Por consiguiente, la Universidad Católica de Villanueva fue afectada. El gesto fue contestado por el claustro de profesores de dicha universidad (Diario de la Marina, 1959b) y por algunos prelados cubanos, quienes se valieron de encíclicas y cartas circulares (COCC, 1995). En dicha respuesta se destacó el arzobispo de Santiago de Cuba monseñor Pérez Serantes, el mismo que durante la guerra civil hizo varios llamados para la búsqueda de una solución pacífica a la crisis (COCC, 1995). Un segundo momento en el camino de la degradación de relaciones Estado-Iglesia en Cuba lo ubico cuando los obispos cubanos intervienen a causa de las ejecuciones de militares y civiles que habían servido y apoyado a la dictadura de F. Batista. En enero del ' 59 el gobierno revolucionario había establecido los llamados Tribunales revolucionarios (Machover, 2011) con la finalidad de hacer justicia a quienes habían servido a la tiranía. Muchos de los procesos judiciales carecieron de ética, y en algunos casos adquirieron el matiz de shows (Machover, 2011). Los procesos se celebraron en estadios y otros lugares públicos recibiendo amplia cobertura mediática. Las ejecuciones fueron también cubiertas por la prensa y por la televisión (Bohemia, 1959). El 29 de enero de 1959, el arzobispo Pérez Serantes hace leer en las iglesias de su arquidiócesis una carta circular donde aborda la cuestión de los fusilamientos. En dicho documento el arzobispo aprueba el derecho que le asiste a la revolución a aplicar la pena de muerte, a la vez que hace un llamado a la utilización de la misericordia como primer recurso en el tratamiento a los condenados (Serantes, 1959b).

Revista Cultura \& Religión Vol. XIII, 2019 Nº 1 (enero-junio)

Cómo citar este artículo: Valencia, F. (2019). "La iglesia católica cubana: entre el vaticano II y la revolución marxista (1959 - 1966)”. Revista Cultura \& Religión. Vol. 13(1). pp. 4-23. 
El tercer momento en el deterioro de las relaciones Iglesia-Estado llega cuando, a fines del '59, la Iglesia Católica reacciona frente al evidente viraje de la revolución cubana hacia la izquierda marxista. El catolicismo reacciona convocando a un congreso de reafirmación de la fe católica, el primer Congreso Nacional Católico (Congreso Nacional Católico, 1959). El Congreso Nacional Católico se celebró entre el 27 y 29 de noviembre de 1959, y tuvo por nombre "Congreso en Defensa de la Caridad". De este evento, primero de su tipo en Cuba, destacamos dos momentos: el primero es la lectura del discurso inaugural, tenida por el obispo de Matanzas, Alberto Martín Villaverde. El segundo es el radiomensaje leído por el papa Juan XXIII la noche de la clausura. El discurso inaugural del Obispo Villaverde declara el propósito por el cual la Iglesia Católica convocó al Congreso:

Este Congreso, que debió haberse llamado Congreso Católico en defensa de la Caridad, era necesario, porque hoy como nunca, se pretende arrancar del hombre hasta la idea de Dios, y sin Dios, se quita la única razón del verdadero amor entre los hombres" (Villaverde, $1959 \mathrm{~s} / \mathrm{n}$ ).

Para el presente trabajo se imponen algunas consideraciones sobre el discurso inaugural del Congreso Nacional Católico. El documento es una mezcla de mensaje político con reafirmaciones cristianas, y está construido en torno a dos ejes; la apología apasionada del catolicismo y el rechazo al proyecto marxista. En tanto documento político, el discurso se opone al proyecto marxista sin llegar a esbozar otro que supere al que intenta criticar. Este hecho parece emanar de la limitada capacidad teórica de la Iglesia para comprender los precipitados cambios que vivía la nación y que la involucraban a ella. El discurso, visto como un documento pastoral, en lugar de orientaciones hacia el pueblo católico, contiene una serie de declaraciones reunidas bajo el título de "Credo Social Católico". Dicho credo constituye los ejes que definen el pensamiento sociopolítico de la jerarquía católica cubana. El documento declara, además, que la Iglesia apoya la "justicia social, pero cristiana" (Villaverde, $1959 \mathrm{~s} / \mathrm{n}$ ) siendo este tema, justicia social, el punto donde se bifurcan las visiones de la Iglesia y del proceso político cubano. El obispo Villaverde parece confundir los conceptos de pueblo católico cubano con el de pueblo cubano, o cuanto menos, intenta dar la imagen de un pueblo cubano donde, quizá como en el caso español, la catolicidad fue el cemento ideológico que unificó la nación. Finalmente, el Concilio Vaticano II es el gran tema ausente -ni siquiera se menciona- en una época donde la iglesia "universal" ya se preparaba para el magno evento.

El otro momento importante del Primer Congreso Nacional Católico fue la lectura del radiomensaje de Juan XXIII (Juan XXIII, 1959). El discurso del pontífice llama más nuestra atención por lo que omite que por lo expresa. A primera vista, el radiomensaje parece revelar que los eventos que se suceden en Cuba no son ajenos al Vaticano. No obstante, la ausencia de orientaciones específicas, en un momento en que la confusión de la iglesia limita su acción a la vez que reclama que se le oriente desde instituciones que poseen más experiencia y visión, nos inclina a pensar que el radiomensaje de Juan XXIII, no es más que una formalidad del Vaticano. El radiomensaje, al igual que otros documentos producidos por el catolicismo cubano de la época, tampoco menciona el concilio Vaticano II. Omisión contradictoria, si se

Revista Cultura \& Religión Vol. XIII, 2019 № 1 (enero-junio)

Cómo citar este artículo: Valencia, F. (2019). "La iglesia católica cubana: entre el vaticano II y la revolución marxista (1959 - 1966)”. Revista Cultura \& Religión. Vol. 13(1). pp. 4-23. 
considera que el concilio en preparación tenía por objetivo fomentar una mayor inserción de la Iglesia en los procesos sociales que constituían su entorno (Alberigo, 1993).

El "Primer Congreso Nacional Católico" es uno de los últimos eventos públicos del catolicismo cubano y él expresa las tensiones entre la Iglesia Católica y el proyecto sociopolítico en construcción. En los próximos años, en la medida en que el gobierno se radicaliza hacia el comunismo, el catolicismo cubano será forzosamente desplazado hacia la periferia social, entrando en su fase de silencio y de subsistencia. Cualitativa y cuantitativamente hablando, la Iglesia Católica experimentará un retroceso que la acercará a los inicios del siglo XX. Ahora bien, ¿Cómo ocurre este proceso de desplazamiento hacia la periferia social?

\section{La desarticulación y marginación del catolicismo cubano en tiempos de concilio}

En la desarticulación del catolicismo cubano no observamos etapas definidas, el proceso ocurre en el corto período que se extiende entre 1961 y 1966. Observamos, más bien, acciones que se yuxtaponen, emanadas de políticas conscientemente encaminadas a aislar social y políticamente al catolicismo cubano y a reducir su capacidad de interacción y comunicación con la sociedad. A nuestro juicio, las acciones que más debilitaron al catolicismo cubano fueron: la pérdida de su infraestructura educativa; el éxodo de sus agentes pastorales (por diversos factores); la pérdida de sus medios de comunicación y, finalmente, el estado general de falta de derechos y de garantías constitucionales que desprotegió a la Iglesia, haciéndola vulnerable.

\section{Pérdida de la infraestructura educativa}

En 1961 ocurre un hecho que acelera el conflicto Iglesia católica-Estado. El 17 de abril, un día después de la declaración hecha por Fidel Castro del carácter socialista de la revolución (Lara, López \& Caram, 2008), un grupo de cubanos que habían emigrado hacia los Estados Unidos protagoniza la llamada invasión de Bahía de Cochinos (Rivas, 2017). La invasión de cubanos, no de mercenarios como la historiografía cubana ha querido mostrar (i.e. Cantón \& Silva, 2009, p. 53-60), fracasó, la invasión fue repelida en apenas 72 horas. Lo interesante para nuestra investigación es que, entre los expedicionarios se encontraban tres sacerdotes católicos (Treto, 1987). En la mochila del padre Ismael de Lugo, "Jefe de los servicios eclesiásticos de la brigada de asalto" (Castro, 1961a), fue encontrado un documento expresamente político (Rodríguez, 2005) el "Llamado al pueblo cristiano de Cuba" (Treto, 1987, p. 44). El documento, reflejo de una acción personal del padre Ismael, y no de una acción institucional (Castro, 1961a), creó una situación embarazosa a la Iglesia católica cubana. Anteriormente, en marzo de 1961, durante la captura de un grupo contrarrevolucionarios en la Sierra del Escambray, en la antigua provincia de Las Villas, había sido aprehendido el sacerdote español Francisco López Blazquez (Paz-Sáchez, 2001). Según Manuel de Paz-Sánchez, (2001, p. 111) "lo grave del asunto era que el presbítero

Revista Cultura \& Religión Vol. XIII, 2019 Nº 1 (enero-junio)

Cómo citar este artículo: Valencia, F. (2019). "La iglesia católica cubana: entre el vaticano II y la revolución marxista (1959 - 1966)”. Revista Cultura \& Religión. Vol. 13(1). pp. 4-23. 
ejercía su misión pastoral entre los grupos de la resistencia contrarrevolucionaria, con el permiso de sus superiores". Ambos hechos fueron interpretados como un acto de intromisión de la Iglesia en los asuntos políticos de la revolución (Paz-Sáchez, 2001).

El $1^{\circ}$ de mayo de 1961, el ya primer ministro de Cuba, Fidel Castro (1961a), pronuncia un discurso donde plantea la intención de la revolución de reducir la acción de la Iglesia a los estrechos límites del templo, expropiando sus instituciones educativas y no educativas. Dicha intervención, por su fecha y contenido (Frei Betto, 1985), nos parece la respuesta a lo que Fidel interpreta como una interferencia de la iglesia en el camino de la construcción de la sociedad socialista. En dicho discurso la Iglesia es acusada de haberse involucrado en un "campaña contrarrevolucionaria (sic.)" (Castro, 1961a). Posteriormente, en 1985, reconstruyendo los hechos en entrevista con Frei Betto, Fidel expresa:

[...] una gran parte del clero era extranjero, y de éste, una gran parte era español [...], muy permeado de las ideas reaccionarias, ideas de derecha, ideas nacionalistas españolas, e incluso, de las ideas franquistas. Cuando aquella gente trata de utilizar la Iglesia como instrumento, como partido contra la Revolución, es cuando surgen los primeros conflictos con la Iglesia (Betto, 1985, p. 209)

Las nacionalizaciones anunciadas por Fidel Castro se materializan a partir del 6 de junio de 1961, mediante la ley de "Nacionalización General y Gratuita de la Enseñanza" (Bell, López \& Caram, 2008: 145 - 147). En consecuencia, todos los centros educativos del país pasaron al sector público, la educación, además, sería gratuita a todos los niveles, la ley afectó a cerca de 70 mil estudiantes (Paz-Sáchez, 2001). La lectura crítica de la citada ley sugiere que la nacionalización de la educación responde más a la necesidad del estado marxista de ideologizar la educación (Bell et al., 2008), que de dotarla de un carácter secular y laico. Si bien la ley surge del conflicto Estado-Iglesia católica (Betto, 1985), su aplicación se extendió a todo el sistema educativo privado, más allá de la pertenencia confesional de sus propietarios.

La expropiación del catolicismo fue tan radical que, en 1966, justo cuando el catolicismo se aprestaba a iniciar la fase de recepción de las enseñanzas conciliares, el gobierno cubano confiscó el seminario El Buen Pastor, la institución de formación pastoral más moderna del catolicismo cubano en la época (Márquez, 1993). Su ubicación geográfica fue el pretexto que justificó dicho despojo. El encontrarse al norte de La Habana lo convertía en plaza ideal para la instalación de una unidad militar destinada a proteger la capital en caso de una agresión estadounidense (Márquez, 1993). La misma suerte corrieron los centros asistenciales con los que contaba la Iglesia antes de 1959 (CEC, 1987).

\section{El éxodo de los agentes pastorales}

La nacionalización de la enseñanza y la expropiación de los edificios e inmuebles docentes (Bell et al., 2008), tuvo un efecto doble sobre el catolicismo cubano. Por un lado, despojó a la Iglesia de uno de sus más importantes instrumentos de influencia sobre la sociedad. Por otro, afectó profundamente a varias órdenes religiosas cuyas funciones se

\section{Revista Cultura \& Religión Vol. XIII, 2019 Nº 1 (enero-junio)}

Cómo citar este artículo: Valencia, F. (2019). "La iglesia católica cubana: entre el vaticano II y la revolución marxista (1959 - 1966)”. Revista Cultura \& Religión. Vol. 13(1).pp. 4-23. 
vinculaban con la educación (CEC, 1987). Tal fue el caso de las Missionnaires de l'Immaculée conception, quienes enseñaban en siete colegios cubanos (Loranger, 1971), y de los Pères des missions étrangères, ambas órdenes con sede en Quebec, Canadá ${ }^{3}$. La conjunción de estos dos hechos provocó un primer éxodo de sacerdotes, religiosos y religiosas en 1961. En el mes de junio el barco Marqués de Comillas devolvió a España cerca de cuatrocientos sacerdotes, religiosos y religiosas españoles y de otras nacionalidades (PazSánchez, 2001). El 16 de septiembre (Guerra \& Maldonado: 2009), el buque español Covadonga trasladaba cerca de 150 agentes pastorales hacia España. La liquidación de la enseñanza privada en Cuba provocó el éxodo concomitante de un importante número de agentes pastorales cuyo ministerio en la Isla se relacionaba con la educación.

Pero el éxodo de agentes pastorales obedeció también a otras causas. A partir de testimonios personales y de información aportada por otros autores (Paz-Sánchez, 2001), podría hablarse también de la expulsión más o menos disimulada de un número importante de agentes pastorales. En su afán por desarticular el catolicismo, el gobierno se valió de métodos cuestionables. Según la revista ecclesia:

[...] la policía, equivalente a la NKVD, visita al sacerdote o religioso y le dice que tiene cinco días para abandonar el país. Con esta jugada pretende Castro que no haya una campaña internacional contra él e, incluso, trata de engañar a la Nunciatura y dar seguridades que luego no cumple (citado por PazSánchez, 2001: 120).

En otros casos, el sacerdote, luego de ser acusado de poseer vínculos con la contrarrevolución o con la CIA, le era comunicada su expulsión (Alfonso, 1985), otros, ante la incertidumbre, abandonaban el país en gesto aparentemente voluntario. Para varios autores (Paz-Sánchez, 2001; Alfonso, 1985) lo sucedido alcanzó proporciones de una persecución religiosa al más puro estilo soviético.

En 1968 el arzobispo primado de Cuba, Enrique Pérez Serantes, estimaba que en el occidente de la isla existía une proporción de un sacerdote por 35 mil habitantes, en el oriente del país esta cifra ascendía a un sacerdote por 70 mil almas (Uría, 2011). Según François Hutart (1963), durante los años ‘60, en América Latina existía una proporción de un sacerdote por cada 5410 habitantes. Contrastando las cifras anteriores, es notable el efecto negativo de las políticas del gobierno sobre el catolicismo cubano. En cifras absolutas, Cuba fue campo misionero para cerca de 200 sacerdotes (COCC, 1995) entre, aproximadamente, siete millones de habitantes (Pyramide.net).

\section{Las Unidades Militares de Ayuda a la Producción}

Otra de las acciones que repercutió negativamente en la estabilidad del catolicismo cubano -en miembros y clero - fue la creación en 1965 de las llamadas UMAP, acrónimo

3 Testimonio del sacerdote canadiense Dénis Castonguay p.m.é. Entrevista realizada el 11 de febrero de 2017 (usado con permiso del entrevistado).

Revista Cultura \& Religión Vol. XIII, 2019 Nº 1 (enero-junio)

Cómo citar este artículo: Valencia, F. (2019). "La iglesia católica cubana: entre el vaticano II y la revolución marxista (1959 - 1966)”. Revista Cultura \& Religión. Vol. 13(1). pp. 4-23. 
de Unidades Militares de Ayuda a la Producción. El origen de las UMAP parece relacionarse con la urgencia económica creada en 1965 como resultado de la caída del precio del azúcar, principal producto exportable de Cuba. En tales circunstancias, el aumento del volumen de producción fue la solución pensada con fin de mantener estables los ingresos. El aumento de la producción se lograría mediante al aumento de los factores involucrados en la fabricación del azúcar y no recurriendo al incremento de la productividad. El 2 de enero de 1965, Fidel (Castro Ruz, 1965) afirma que para realizar la zafra del año en curso sería necesario la movilización de todos. Las organizaciones existentes, surgidas en remplazo de la sociedad civil, fueron los canales para involucrar a la casi totalidad de la sociedad en las labores agrícolas, pero ¿qué hacer con aquellos sectores sociales aún no involucrados en la construcción del socialismo? Dichos individuos fueron obligados a participar en las labores agrícolas por medio de las UMAP (Muñoz, 2007).

Las UMAP, describe uno de los pasajes más sombríos de la historia de la revolución cubana, y uno de los temas más evitados por la historiografía revolucionaria actual. A las UMAP fue enviada una sola categoría social, los antisociales (Muñoz, 2007). Categoría formada por pastores de casi todas las denominaciones cristianas y de sectas pseudocristianas, como testigos de Jehová (Ramos, 1998), laicos y miembros de iglesias (Alfonso, 1985), homosexuales y otros individuos cuya moral no se correspondía con la moral socialista (Galló, 1963). Para hacer la vida de los internos más difícil, algunos presos comunes fueron enviados a las UMAP (Muñoz, 2007). En lo que interesa a la Iglesia Católica, tres sacerdotes fueron enviados a las Unidades Militares de Apoyo a la Producción, ellos son: Armando Martínez, cura de San Juan Bautista, en la provincia de Matanzas; Alfredo Petite, cura de la Catedral de La Habana; y Jaime Ortega Alamino, cura de la ciudad de Cárdenas, también en la provincia de Matanzas (Alfonso, 1985), este último actual cardenal de la Iglesia Católica en Cuba. Según Abel R. Castro Figueroa inicialmente, el gobierno previó enviar a la UMAP cinco sacerdotes cada año (Figueroa, 2012). Las pésimas condiciones de vida y de maltrato a que fueron sometidos los reclutados, las largas jornadas de trabajo en condiciones de explotación y la indignidad misma con que fueron tratados los individuos enviados a las UMAP - condiciones semejantes a las de un campo de concentración - (Ros, 2004), sembró el terror en las comunidades religiosas (Crahan, 1989; Muñoz, 2007), estimulando el éxodo ya no solo entre el clero, sino también en los laicos.

\section{Pérdida de los medios de comunicación}

Otro momento importante en el retroceso vivido por el catolicismo cubano en tiempos de concilio, fue la pérdida de sus medios de comunicación. Entre 1959 y 1961 el gobierno se concentra en liquidar la libertad de prensa y sustituirla por una prensa alineada a los intereses del proyecto socialista (Valdés, 2008). Para el profesor Nicolás J. M. González (2012), las razones que llevan a la revolución cubana, o más bien a Fidel Castro, a la liquidación de la libertad de prensa son; de un lado, la necesidad de eliminar los debates y cuestionamientos surgidos alrededor de ciertas políticas aplicadas por la revolución en diarios nacionales como

Revista Cultura \& Religión Vol. XIII, 2019 Nº 1 (enero-junio)

Cómo citar este artículo: Valencia, F. (2019). "La iglesia católica cubana: entre el vaticano II y la revolución marxista (1959 - 1966)”. Revista Cultura \& Religión. Vol. 13(1). pp. 4-23. 
"Prensa Libre", "El Diario de la Marina" y en artículos publicados en revistas como Times y Life. Por otro, sin el control de los medios no sería posible ni el avance de la revolución ni el viraje hacia el marxismo. Para reeducar a las masas en la ideología marxista, había que eliminar toda otra interpretación, ideología o proyecto sociopolítico que rivalizara, o que cuestionara, el proyecto marxista.

La lapidación de la libertad de prensa en Cuba es un proceso que avanza entre 1959 y 1962. En 1959 el gobierno revolucionario crea, en un intento de darle a la nación una política cultural sólida, el Instituto Cubano de la Industria y el Arte Cinematográficos (ICAIC) y la Imprenta Nacional (Bell et al., 2006). Según los estatutos fundacionales del ICAI este fue creado con el fin de "organizar, establecer y desarrollar la industria cinematográfica atendiendo a criterios artísticos enmarcados en la tradición cultural cubana, y en los fines de la Revolución [...]" (Bell et al., 2006, p.147). Por su parte, la creación de la imprenta nacional de Cuba obedeció, de un lado a la necesidad de abaratar los precios del material escolar e instructivo que se emplearía en la nueva reeducación de la sociedad, y del otro, crear un espacio para que la "nueva generación revolucionaria" (Bell et al., 2006, p. 151) hiciera llegar el pueblo su mensaje cultural. La producción cinematográfica, así como la publicación de libros pasaba a manos del gobierno. Dos años después, el 22 de agosto de 1961, el gobierno dio un paso más en el control de la producción literaria e intelectual al crear la Unión de Escritores y Artistas de Cuba (Gallardo, 2009). Posteriormente, en 1962, el gobierno crea el Instituto Cubano de Radiodifusión (Bell et al., 2009), en los párrafos que explican su fundación se lee: "[...] los medios de comunicación la radio y la televisión son en Cuba los más extendidos y eficaces en la tarea de informar al pueblo, promover su educación, elevar su consciencia socialista [...]" (Bell et al., 2009, p. 459). El Instituto, dependiente del Consejo de Ministros (Bell et al., 2009, p. 459), tendría entre otros fines el de "dirigir [...] todas las actividades relativas a la radio y la televisión, tanto las nacionales como las que originadas en Cuba estén dirigidas al público de otros países" (Bell et al., 2009, p. 459). La creación de estas instituciones materializó el itinerario hacia el monopolio de los medios por parte del Estado y hacia la censura en Cuba.

Con relación al catolicismo, en 1960 éste posee una discreta, pero visible, actividad en los medios de comunicación (Amador, 2005). Sin publicación oficial, el catolicismo cubano se servía de otros medios para proyectar su pensamiento y puntos de vista hacia la sociedad (Moragues, 2008). De las publicaciones periódicas del catolicismo una de las más importantes fue la revista "La Quincena". La revista había sido creada bajo la premisa de dar "una respuesta cristiana a los problemas de hoy" (Santalices, 2005, p.408). Los números publicados entre 1959 y 1960 se involucran abiertamente en los debates sobre la revolución, esforzándose por demostrar la relación armónica entre los principios del cristianismo y la praxis de la revolución cubana (Montenegro, 2008). En 1960, la revista sufre un cambio, la jerarquía franciscana remplaza el padre Biaín por Mariano Errasti en su dirección, a Biaín, además, le es prohibido predicar (Uría, 2011). El 17 de abril de 1961 la sede de la revista es intervenida y clausurada por las milicias revolucionarias (Paz-Sánchez, 2001). "La Quincena", a causa de su contenido, fue considerada por el padre C. Manuel de Céspedes,

Revista Cultura \& Religión Vol. XIII, 2019 Nº 1 (enero-junio)

Cómo citar este artículo: Valencia, F. (2019). "La iglesia católica cubana: entre el vaticano II y la revolución marxista (1959 - 1966)”. Revista Cultura \& Religión. Vol. 13(1). pp. 4-23. 
"la mejor ventana de la modernidad católica para nuestra iglesia en este siglo" (Céspedes 2000, p. 143).

De modo que, para 1965 ya el estado marxista había logrado el monopolio de la información en la isla, según Abel C. Figueroa:

Todos los medios de difusión y de enseñanza estaban en manos del estado y expresaban la posición del gobierno respecto a cualquier asunto. Ya no había otra opción informativa ni interpretativa de los hechos, ya sea a nacional o internacional (Figueroa, 2001, p. 55-56).

En lo adelante, el Estado asumió el monopolio de la información transmitida a la sociedad (Gallardo, 2009), convirtiéndose ésta en "arma de la revolución" (Valdés Paz, 2008: 26); la Iglesia no pudo retener ningún espacio en los medios de comunicación. No obstante, hay una excepción, el 4 de noviembre de 1962, a iniciativa del padre Donato Cajero s.j. surge en la ciudad de Sancti Spíritus la publicación "Vida Cristiana" (Amador, 2005), única publicación que sobrevivió hasta 1991, cuando una nueva política de tolerancia religiosa permite la impresión de otras publicaciones católica en Cuba (Amador, 2005). "Vida Cristiana" era una sola hoja, impresa a dos caras, con noticias muy sintéticas sobre la evolución del catolicismo nacional y mundial. Siendo la única publicación católica permitida en la isla, se convirtió en plataforma "para divulgar los documentos del Concilio Vaticano II, y los comunicados y mensajes de la Conferencia de Obispos Católicos de Cuba" (Permús, 2019).

La presencia católica en los programas televisivos corrió igual suerte. Cuando a partir de 1960 se inicia el proceso de reconfiguración política que condujo a la formación del partido único, el entonces partido de gobierno -las Organizaciones Revolucionarias Integradas - (antecedente primero del PCC) creó la Comisión de Orientación Revolucionaria (COR), encargada de vetar o aprobar el contenido de los programas trasmitidos en la televisión nacional (Valdés, 2008). Dicho gesto presupuso el cierre de los espacios de contenidos religiosos en la televisión nacional.

\section{Una Iglesia sin protección legal.}

Por último, analizo el marco legal en el cual ocurre la marginalización del catolicismo en Cuba. Cuando el primero de enero de 1959 la revolución triunfa, el país ha vivido en la inconstitucionalidad desde 1952. En tales condiciones, el retorno a la democracia y a la constitucionalidad era un imperativo. En fecha tan temprana como el 3 de enero de 1959, el gobierno provisional revolucionario restaura la Constitución vulnerada, la de 1940 (Bell et al., 2006).

El siguiente mes, Fidel Castro hace evidente su intención de recuperar la democracia en todas las instituciones, convocando a "elecciones generales en un plazo de tiempo que no va a ser extenso" (Castro, 1959). El 7 de febrero, el nuevo gobierno redacta y sanciona la nueva Ley Fundamental de la República, la cual, salvo en pocos artículos, reproducía la

Revista Cultura \& Religión Vol. XIII, 2019 Nº 1 (enero-junio)

Cómo citar este artículo: Valencia, F. (2019). "La iglesia católica cubana: entre el vaticano II y la revolución marxista (1959 - 1966)”. Revista Cultura \& Religión. Vol. 13(1). pp. 4-23. 
Constitución de 1940 (Bell et al., 2006). La Ley Fundamental, en su carácter de provisional, establecía el marco legal al interior del cual la revolución debía establecer su itinerario hacia el restablecimiento del estado de derecho y de la democracia en Cuba. En los hechos, como ya se ha dejado entrever, la democracia nunca fue restablecida; la desarticulación del capitalismo y la creación de las bases del sistema comunista se realizaron dictando leyes que negaban la Ley Fundamental de febrero de 1959.

La pregunta es; ¿Cuál es el punto de inflexión a partir del cual a la sociedad -de la cual el catolicismo forma parte - le son vulnerados sus derechos y es arrastrada a implicarse en un proyecto político impuesto desde arriba? Para responder, me remito a uno de los discursos más complejos tenidos por Fidel Castro en 1961: Palabras a los intelectuales (Castro, 1961b). En dicha alocución, cuyo público primero no son los católicos, Fidel expresa:

Dentro de la Revolución todo, contra la revolución nada [...]. Dentro de la Revolución, todo; contra la Revolución, ningún derecho [...] Y esto no sería ninguna ley de excepción para los artistas y para los escritores. Esto es un principio general para todos los ciudadanos, es un principio fundamental de la Revolución. Los contrarrevolucionarios, es decir, los enemigos de la Revolución, no tienen ningún derecho contra la Revolución. (Castro, 1961b).

Este discurso, que será la piedra angular de la política cultural durante el período de construcción del comunismo, reveló el colapso del estado de derecho en Cuba. La frase "Contra la revolución ningún derecho", expresada por el líder de la Revolución, desamparaba de facto a todos aquellos para quienes el giro hacia el marxismo se alejaba de sus intereses particulares o sociales. Según el profesor Emilio J. Gallardo-Saborido (2009, p. 59), "Los pasos que condujeron a «Palabras a los Intelectuales» se pueden y deben considerar desde diversos campos: la evolución de los medios de comunicación, las relaciones con la Iglesia, el control de las universidades, etc."

Entre la invalidación de la Ley Fundamental de 1959 y la aprobación de la primera constitución socialista de Cuba en 1976, hay un periodo irregular de ausencia de garantías constitucionales, donde las acciones del estado marxista no pueden ser ni siquiera contestadas. Este periodo de no-constitucionalidad fue el marco al interior del cual el catolicismo cubano fuera retirado forzosamente al margen de la sociedad, sin poder apelar a ningún recurso legal que le protegiera.

Finalmente, hay dos aspectos que no quisiéramos obviar en el presente artículo. Primeramente, aun cuando la Iglesia Católica Cubana vive la época conciliar en las condiciones antes descritas, ésta hace un intento por involucrarse a tiempo real en el concilio y vivir el "estado de concilio" experimentado por otras iglesias. En 1960 los obispos Enrique Pérez Serantes y Carlos Ríu Anglés, envían una carta a la comisión antepreparatoria (Acta et documenta concilio æecuménique Vaticano II, MCMLX) conteniendo las recomendaciones de la Iglesia Cubana. El documento en cuestión trata sobre la liturgia y la eucaristía, el lugar de los laicos en la misión de la Iglesia y la unidad entre laicos, sacerdotes y obispos en la misión de la Iglesia. En segundo lugar, el catolicismo cubano estuvo representado en el concilio

Revista Cultura \& Religión Vol. XIII, 2019 Nº 1 (enero-junio)

Cómo citar este artículo: Valencia, F. (2019). "La iglesia católica cubana: entre el vaticano II y la revolución marxista (1959 - 1966)". Revista Cultura \& Religión. Vol. 13(1). pp. 4-23. 
Vaticano II. Cuatro obispos formaron la delegación cubana al concilio, ellos son: José Maximino Domínguez, Obispo de Matanzas; Fernando Azcárate, Obispo Auxiliar de La Habana; Carlos Ríu Anglés, Obispo de Camagüey y Manuel Rodríguez Rozas, Obispo de Pinar del Río (Gómez Treto, 1987). El regreso de los padres conciliares dio origen a una muy discreta, pero real, fase de recepción de las enseñanzas conciliares en la Isla.

\section{Consideraciones finales}

Retomemos las dos preguntas planteadas en la introducción del presente trabajo: ¿por qué en Cuba, país católico, el concilio Vaticano II no es vivido con la misma intensidad que en el resto de América Latina? ¿Cómo vivió el catolicismo cubano el primer Concilio celebrado en un mundo globalizado? Primeramente, el catolicismo cubano vive el período preparatorio, la celebración del concilio y la primera fase de recepción (hasta 1966), en una profunda desconexión con el catolicismo "universal", concentrándose más en la solución de sus problemas internos que en aquellos que convocaban al magno evento. Dicha actitud no deriva de la enajenación de la Iglesia Católica Cubana, sino de las condiciones sociopolíticas en las cuales el catolicismo cubano ha de vivir el concilio. En 1959 se establece en Cuba un gobierno que adoptaba el marxismo como metodología política para la reconstrucción de la nación y con ello, se adhiere al comunismo internacional. La adopción del marxismo introdujo nuevas categorías y conceptos tanto para explicar la evolución de la sociedad cubana como para proyectar su reconstrucción. Entre los conceptos que más afectarían la evolución del catolicismo cubano estarían el de "lucha de clases", concepto inherente a la teoría materialista de la historia. En consecuencia, el desmontaje del sistema capitalista presupuso la desarticulación de la iglesia, dado que ésta, según la interpretación marxista de la historia, no era otra cosa que la expresión y el sustento espiritual de la explotación de una clase social sobre otra. Así, entre los años 1959 y 1965, como parte de la instauración del sistema comunista, la iglesia es despojada de los recursos - materiales y humanos- que constituían sus mejores vínculos con la sociedad, y con los cuales había colaborado en el desarrollo de la nación cubana. La Iglesia católica cubana es prácticamente obligada a recluirse en los templos y a asumir una actitud de conservación, y no de expansión como fue el caso del catolicismo latinoamericano.

En segundo lugar, y sin adentrarnos en la fase de recepción práctica, pues sobrepasa las fronteras temporales del presente trabajo, lo antes expuesto justifica también porqué la recepción de las enseñanzas conciliares en Cuba no provoca en el catolicismo cubano la reflexión sociopolítica compleja que provocó en el catolicismo latinoamericano. En el resto de América Latina, el Vaticano II condujo a la Iglesia a adoptar una profunda actitud de dialogo con la cultura y con la sociedad dando como resultado el período más rico de la historia de la teología latinoamericana. En Cuba, el exclusivismo sectario del proyecto comunista cerró toda posibilidad a otros sectores sociales no simpatizantes con el marxismo de participar en la reconstrucción de la sociedad y de implicarse en la reflexión sobre la sociedad desde bases teóricas no marxistas. Es en la década de los '70, que el catolicismo

Revista Cultura \& Religión Vol. XIII, 2019 Nº 1 (enero-junio)

Cómo citar este artículo: Valencia, F. (2019). "La iglesia católica cubana: entre el vaticano II y la revolución marxista (1959 - 1966)”. Revista Cultura \& Religión. Vol. 13(1). pp. 4-23. 
cubano reflexionará a partir de la Biblia sobre una teología que responda a las necesidades particulares de la sociedad cubana; me refiero a la Teología de la Reconciliación, pero dicho fenómeno sobrepasa también los límites temporales de nuestro trabajo.

\section{Referencias Bibliográficas}

Acerca de la Religión, la Iglesia y los Creyentes, 1952. La Habana: Editora Política. Acta et documenta concilio acuménique Vaticano II apparando, series I volumen II, consilia et vota episcoporum ac praelatorum, America septemtrionalis et centralis, MCMLX. Paris VI: Typis poliglottis vaticanis.

Alberigo, G. (1993). Historia de los Concilios Ecoménicos. Salamanca: Ediciones Sígueme. Alfonso, P. (1985). Cuba, Castro y los Católicos, del humanismo revolucionario al marxismo totalitario. Miami: Ediciones Hispamerican Books.

Amador, C. (2005). "Los medios de comunicación de la Iglesia: nueva realidad después del ENEC”. En Verdad y Esperanza. La Habana: Publicación de la Unión Católica de Prensa de Cuba, pp. 57 - 59.

Antoine, Ch. (1999). Guerre Froide et Église Catholique. L'Amérique Latine. Paris: Les Éditions du Cerf.

Bell, J., López, D. \& Caram, T. (2006). Documentos de la Revolución Cubana 1959. La Habana: Editorial de Ciencias Sociales.

Bell, J., López, D. \& Caram, T. (2007). Documentos de la Revolución Cubana 1960. La Habana: Editorial de Ciencias Sociales.

Bell, J., López, D. \& Caram, T. (2008). Documentos de la Revolución Cubana 1961. La Habana: Editorial de Ciencias Sociales.

Bell, J., López, D. \& Caram, T. (2009). Documentos de la Revolución Cubana 1962. La Habana: Editorial de Ciencias Sociales.

Betto, F. (1985). Fidel y la Religión, conversaciones con Frei Betto. La Habana: Oficina de publicaciones del Consejo de Estado.

Bolaños, J. Bofill, A. \& Pageaga, J. (1959b). "Declaración de los claustros de Villanueva y La Salle sobre la invalidación de títulos". Diario de la Marina. 127(11) (14 de enero).

Cantón, J. \& Silva, A. (2009). Historia de Cuba, 1959 - 1999, Liberación nacional y Socialismo. La Habana: Pueblo y Educación.

Carta Semanal (1953). No 16, 20 de octubre.

Castro, F. (1959). "Discurso pronunciado por el comandante Fidel Castro Ruz, primer ministro del gobierno revolucionario, en el Colegio de Arquitectos, el 16 de febrero de 1959", Consultado en 3 de enero de 2019: http://www.cuba.cu/gobierno/discursos/1959/esp/f160259e.html.

Castro, F. (1961). "Discurso Pronunciado por el Comandante Fidel Castro Ruz, primer ministro del gobierno revolucionario de Cuba, resumiendo los actos del día internacional del trabajo. Plaza cívica, $1^{\circ}$ de mayo de 1961", Consultado en 2 de febrero de 2009: http://www.cuba.cu/gobierno/discursos/1961/esp/f010561e.html.

Revista Cultura \& Religión Vol. XIII, 2019 Nº 1 (enero-junio)

Cómo citar este artículo: Valencia, F. (2019). "La iglesia católica cubana: entre el vaticano II y la revolución marxista (1959 - 1966)”. Revista Cultura \& Religión. Vol. 13(1). pp. 4-23. 
Castro, F. (1961a). "Discurso pronunciado por el comandante Fidel Castro Ruz, primer ministro del gobierno revolucionario de cuba, resumiendo los actos del día internacional del trabajo. Plaza civica, $1^{\circ}$ de mayo de 1961", Consultado en 31 de mayo de 2016: http://www.cuba.cu/gobierno/discursos/1961/esp/f010561e.html.

Castro, F. (1961b). "Discurso pronunciado por el comandante Fidel Castro Ruz, primer ministro del gobierno revolucionario y secretario del PURSC, como conclusión de las reuniones con los intelectuales cubanos, efectuadas en la Biblioteca Nacional el 16, 23 y 30 de junio de 1961", Consultado en febrero de 2019: http://www.cuba.cu/gobierno/discursos/1961/esp/f300661e.html.

Castro, F. (1963). "Discurso pronunciado por el comandante Fidel Castro Ruz, primer ministro del gobierno revolucionario de Cuba, en la clausura del acto para conmemorar el VI Aniversario del asalto al palacio presidencial, celebrado en la escalinata de la universidad de La Habana, el 13 de marzo de 1963 », Consultado en $\begin{array}{llll} & \text { o de } & \text { enero } & \text { de }\end{array}$ http://www.cuba.cu/gobierno/discursos/1963/esp/f130363e.html.

Castro, F. (1965). "Discurso Pronunciado por el comandante Fidel Castro Ruz, primer secretario del PURSC y primer ministro del gobierno revolucionario, en la concentración conmemorativa del sexto aniversario de la revolución, efectuada en la plaza de la revolución, el 2 de enero de 1965", Consultado en 20 de julio de 2016: http://www.cuba.cu/gobierno/discursos/1965/esp/f020165e.html.

Cerutti, H. \& Mondragón, C. (coords. 2006). Religión y política en América Latina: la utopía como espacio de resistencia social. México D.F.: UNAM.

Céspedes, C. M. (2000). "Evolución del pensamiento católico en Cuba, de los orígenes hasta 1959". En Tercer encuentro nacional de Historia de Iglesia Católica y nacionalidad cubana, Memorias. Comisión Nacional de Pastoral de Cultura de Ia COCC Casa Diocesana de La Merced, 6-9 de junio de 2000. Arquidiócesis de Camagüey.

Civeira, F. (2008). Cuba entre 1899 y 1958. Seis décadas de historia. La Habana: Editorial Félix Varela.

Conferencia de obispos católicos de Cuba (1995). La voz de la Iglesia en Cuba, 100 documentos episcopales. México: DF, Obra nacional de la Buena prensa.

Conferencia Episcopal Cubana (1987). Encuentro Eclesial Cubano, Documento Final e Instrucción Pastoral. Roma: Tipografía Juan Bosco.

Congreso Nacional Católico (1959). Folleto mimeografiado. Centro Cultural Félix Varela. La Habana. Cuba.

Cordoví, J \& Murgia, M. (2017). "La regulación de la enseñanza privada en Cuba. Principales proyectos, normativas y polémicas". En Historia Caribe, no. 30 V. XII - enero-junio, pp. $211-243$.

Crahan, M. (1989). Catholicism in Cuba. En Cuban Studies 19. Center for Latin American Studies. University of Pittsburg Press.

Figueroa, A. R. (2012). Quo vadis, Cuba? Religión y revolución. Bloomington: Palibrio.

Revista Cultura \& Religión Vol. XIII, 2019 № 1 (enero-junio)

Cómo citar este artículo: Valencia, F. (2019). "La iglesia católica cubana: entre el vaticano II y la revolución marxista (1959 - 1966)”. Revista Cultura \& Religión. Vol. 13(1). pp. 4-23. 
Floristán, C. \& Tamayo, J. J. (1985). El Vaticano II, veinte años después. Madrid: Ediciones Cristiandad.

Gallardo, J. E. (2009). El Martillo y el Espejo. Directrices de la política cultural cubana (1959-1976). Madrid: Consejo Superior de Investigaciones Científicas.

Galló, G. (1964). Nuestra Moral Socialista. La Habana: Editorial Nacional de Cuba.

García, S. (2000). "Academia Católica de Ciencias Sociales: una Institución al Servicio del Pueblo de Cuba". En Comisión Nacional de Pastoral de Cultura de la COCC, Tercer Encuentro Nacional de Historia Iglesia Católica y Nacionalidad Cubana. Memorias. Camagüey.

Gracio, R. M. \& Bidegain M. (1992). América Latina el Descubierto. Madrid: Iepala.

Grau, E. (1959a). "Prestaron los católicos de Cuba su cooperación decidida a la causa de la libertad. -Fidel Castro". Diario de la Marina. año CXXVIL, no. 5, 7 de enero.

Guerra, S. \& Maldonado, A. (2009) “Historia de la revolución Cubana”. Txalaparta. Navarra.

Hutart, F. (1963). L'Église Latino-américaine à l'heure du concile. Fribourg: Suisse, Bogotá: FERES.

Ivereigh A. (2014). The great reformer. Francis and the Making of a Radical Pope. New York: Henry Holt and Company.

Juan XXIII (1959). "Radiomensaje de su Santidad Juan XXIII a los fieles de Cuba con motivo del I Congreso Católico Nacional y de la Asamblea General del Apostolado Seglar". Domingo 29 de noviembre de 1959, Consultado en 2 de febrero de 2019: https://w2.vatican.va/content/johnxxiii/es/messages/pont_messages/1959/documents/ hf_j-xiii_mes_19591129_cuba.pdf

Létrilliart, P. (2008). "L'Église cubaine : cinquante ans d'expérience « contrerévolutionnaire» ?". Cahiers des Amériques latines, no. 57-58 , pp. 125-141, Consultado en 10 de marzo de 2019 : http://journals.openedition.org/cal/1276.

Loranger, M. (1971). "Historique de la Congrégation des Missionnaires de 1'ImmaculéeConception et des origines de la Société des Missions-Étrangères de Québec". En Sessions d'étude - Société canadienne d'histoire de l'Église catholique, no. 38, pp. 7184. Consultado en 12 de marzo de 2019: https://www.doi.org/10.7202/1007266ar.

Machover J. (2011). El Terror Humanista, Tribunales revolucionarios y paredón en Cuba. Madrid: Editorial Hispano-Cubana.

Marins J., Trevisan M., \& Chanona C. (1977). Comunidades eclesiales de base: origen, contenido, perspectivas. Bogotá: Ediciones Paulinas.

Márquez, O. (1993). "Nuestra Iglesia, entrevista de Orlando Márquez à Monseñor Carlos Manuel de Céspedes". En Palabra Nueva, revista de la Arquidiocesis de La Habana, no 16, año II, pp. 7- 14.

Marx, K. \& Engels, F. (1848). "Manifiesto Comunista", Consultado en 13 de febrero de 2019.[https://sociologia1unpsjb.files.wordpress.com/2008/03/marx-manifiestocomunista.pdf].

Massón, C. (2008). “Cuba: Marxismo, Nacionalismo y Hegemonía 1925-1958”. Revista Izquierdas, 1(1). ISSN 0718-5049, pp. 1-19.

Revista Cultura \& Religión Vol. XIII, 2019 Nº 1 (enero-junio)

Cómo citar este artículo: Valencia, F. (2019). "La iglesia católica cubana: entre el vaticano II y la revolución marxista (1959 - 1966)”. Revista Cultura \& Religión. Vol. 13(1). pp. 4-23. 
Maza, M. (1997). Entre la ideología y la compasión. Guerra y Paz en Cuba, 1895-1903. Santo Domingo: Instituto Pedro Francisco Bono.

Miranda, O. (1995). "El marxismo en el ideal emancipador cubano durante la República neocolonial". En Temas, julio - septiembre, pp. 44-56.

Monseñor, Meurise E. (1998). "Discurso de bienvenida del obispo de Santiago de Cuba, monseñor Pedro Meurise Estiú el 24 de enero de 1998". Consultado en 10 de marzo de 2019: http://www.delafe.com/cardenas/parroqui/meurices.htm.

Moragues, N. J (sf). "La revolución de los medios de comunicación en Cuba", en Temps de Comunicar, Consultado en 2 de enero de 2019: https://www.cesag.org/ghcs/tempsdecomunicar/?p=335.

Morello, G. (2007). "El Concilio Vaticano II y su impacto en América Latina: a 40 años de un cambio en los paradigmas en el catolicismo". En Revista Mexicana de Ciencias Políticas y Sociales, 49(199), pp. 81-104.

Muñoz, A. (2007). Y vimos su gloria. La Habana: Editorial Bautista.

Palacios, M. \& Weinberg, G. (dir. 2008). Historia General de América Latina, vol. VIII. Paris: Ediciones UNESCO, Editorial Trotta.

Paraíso, J. Y. (2013). La perception de la théologie latino-américaine de la libération en République Fédérale d'Allemagne. Paris: L'Harmattan.

Partido Comunista de Cuba (1976). Plataforma programática del Partido Comunista de Cuba: tesis y resoluciones. La Habana: Departamento de Orientación Revolucionaria del Comité del Partido Comunista de Cuba.

Paz-Sánchez, de M. (2011). Zona de Guerra. España y la Revolución Cubana (1960 - 1962). Tenerife: Centro de la Cultura Popular Canaria.

Sitio web de la Conferencia de Obispos Católicos de Cuba. (2016). "Festejan 54 años de Vida Cristiana". Conferencia de Obispos Católicos de Cuba. Consultado en 17 de febrero de 2019: http://iglesiacubana.org/cocc/pages/articles/199.

Population Pyramids of the World from 1950 to 2100. (s/f). Cuba 1965. Consultado en 20 de junio de 2018: https://www.populationpyramid.net/es/cuba/1965

Rama, M. (1990). El Anarquismo en América Latina. Caracas: Biblioteca Ayacucho.

Revista Bohemia (1959). Edición de la Libertad, 2, (enero-febrero), pp. 3-5.

Riccardi, A. (2002). Ils sont morts pour leurs foi. La persécution des chrétiens au XXe siècle. Plon/Mame.

Rivas, S. (2017). Playa Girón: The Cuban Exiles Invasion at the Bay of Pigs. Helion Limited, 2017.

Ros, E. (2004). La UMAP: el Gulag castrista. Miami: Ediciones Universal.

Routhier, G. (2002). Évêques du Québec (1962-1965): Entre Révolution tranquille et aggiornamento conciliaire. Québec: CIEQ.

Routhier, G., Attridge, M. \& Clifford, E. (dir. 2011). Vatican II, Expériences canadiennes. Ottawa : Presses de L’Université D'Ottawa.

Santalices, M. (2005). “Asociaciones y movimientos católicos en Cuba: su proyección social en la República”. en Iglesia Católica y nacionalidad cubana, encuentros nacionales

Revista Cultura \& Religión Vol. XIII, 2019 Nº 1 (enero-junio)

Cómo citar este artículo: Valencia, F. (2019). "La iglesia católica cubana: entre el vaticano II y la revolución marxista (1959 - 1966)”. Revista Cultura \& Religión. Vol. 13(1). pp. 4-23. 
de Historia, T - II, Comisión nacional de Pastoral de Cultura de la Conferencia de Obispos Católicos de Cuba. Miami : Ediciones Universal, pp. 408-409.

Secretariado económico social de la Junta Nacional de Acción Católica Cubana (1953). "Primer Catálogo de Obras Sociales Católicas de Cuba". La Habana, Cuba.

Serantes, E. (1959a). "Circular Vida Nueva". Arzobispado de Santiago de Cuba. Circular fechada el 3 de enero de 1959.

Serantes, E. (1959b). "Circular el justo medio". Arzobispado de Santiago de Cuba. Circular fechada el 29 de enero de 1959.

Shivley, W., (2012). Pouvoir et décision, introduction à la science politique. Montréal: Chenelière.

Silva, A., Civeira, F. \& Loyola, O. (2004). Cuba y su historia. La Habana: Editorial Félix Varela.

Theobald, C. (2009). La réception du concile Vatican II, Accéder à la source. Paris: Éditions du Cerf.

Torres-Cuevas, E. \& Loyola, O. (2001). Historia de Cuba, formación y liberación de la nación, 1492 - 1898. La Habana: Ciencias Sociales.

Treto, R. (1987). La iglesia católica cubana durante la construcción del socialismo en Cuba. La Habana: CEHILA.

Uría, I. (2011). Iglesia y revolución en Cuba. Enrique Pérez Serantes (1883-1968), el obispo que salvó a Fidel Castro. Madrid : Encuentro.

Valdés, J. (2008). "Cuba. La Constitución del poder revolucionario (1959-1963)». En Temas, Cultura, Ideología, Sociedad, 55, julio-septiembre, pp. 18 - 31.

Valencia, F. (2018). "L'Église catholique cubaine, entre réforme politique et réforme ecclésiale : la réception du concile Vatican II à Cuba (1963 - 1998)». Tesis para optar por el título de PhD en Sciences des religions de la Université Laval. Quebec. Canadá.

Van Nieuwenbove, J. (1974). «Les théologies de la libération latino-américaines ». En Le Point Théologique. Théologies de la Libération en Amérique Latine. V 10. Centre d'études et de recherches interdisciplinaires en Théologie (C.E.R.I.T.) de StrasbourgI, pp. $67-95$.

Villaverde, A. (1959). Congreso en defensa de la Caridad. Discurso del Excmo. Señor Alberto Martin Villaverde, obispo de Matanzas, Primer Congreso Nacional Católico. Ciudad de La Habana. Cuba.

Yglesias, M. T. (1976). Cuba primera república, segunda ocupación. La Habana: Ciencias Sociales.

Zanetti O., (2006). La República, notas sobre economía y sociedad. La Habana: Editorial de Ciencias Sociales.

Revista Cultura \& Religión Vol. XIII, 2019 Nº 1 (enero-junio)

Cómo citar este artículo: Valencia, F. (2019). "La iglesia católica cubana: entre el vaticano II y la revolución marxista (1959 - 1966)”. Revista Cultura \& Religión. Vol. 13(1). pp. 4-23. 